\title{
Preparation of Polystyrene Nanoparticles by Seed Polymerization Using Amphiphilic Random Copolymer Micelles as Seeds
}

\author{
Naoki SuZuki,${ }^{1, \dagger}$ Yotaro Morishima, ${ }^{2}$ Susumu ARIMORI,${ }^{1}$ and Takeshi Endo ${ }^{1, \dagger}$ \\ ${ }^{1}$ Henkel Kindai Labratories, 11-6 Kayanomori, Iizuka, Fukuoka 820-8555, Japan \\ ${ }^{2}$ Faculty of Engineering, Fukui University of Technology, 6-3-1 Gakuen, Fukui 910-8505, Japan
}

(Received July 7, 2006; Accepted November 3, 2006; Published December 14, 2006)

\author{
KEY WORDS Polystyrene Particles / Monodisperse Nanoparticles / Amphiphilic Random \\ Copolymers / Polymer Micelles / Seed Polymerization / \\ [doi:10.1295/polymj.PJ2006076]
}

In recent years, with the progress of techniques to prepare monodisperse fine polymer particles, various colloidal polymer particles are being used for practical applications, such as surface coatings,,${ }^{1-3}$ cosmetics, ${ }^{4-7}$ surface modifiers for photo films, ${ }^{8}$ and carriers for virus diagnosis. ${ }^{9-13}$ The sizes of the polymer colloidal particles prepared so far lie in the range from $10 \mathrm{~nm}-$ $10 \mu \mathrm{m}$ depending on the method employed, which includes emulsion polymerization, ${ }^{14}$ microemulsion polymerization, ${ }^{15,16}$ miniemulsion polymerization, ${ }^{17}$ soap-free polymerization, ${ }^{18,19}$ dispersion polymerization, ${ }^{20}$ seed polymerization, ${ }^{21}$ and suspension polymerization. ${ }^{22}$

Among these methods, microemulsion polymerization is the most commonly-used technique to prepare polymer colloids with diameters $<100 \mathrm{~nm}$ and narrow size distributions. ${ }^{15,16}$ Such small polymer particles are desirable for surface coatings because it takes only a short time for film formation and the particles can penetrate easily into porous substrates producing a film with good optical and mechanical properties. ${ }^{1}$ For pharmaceutical applications, colloidal polymer particles are expected to be used as a long-circulating drug delivery vehicle because particles smaller than $\sim 100 \mathrm{~nm}$ can be prevented from being detected by the human body's reticuloendothelial system. ${ }^{13}$ However, a disadvantage of the microemulsion polymerization is that one has to use a large amount of a surfactant and a cosurfactant, i.e., nearly comparable amounts of a surfactant and a monomer may be necessary to be used. This often creates a problem of the purity of final products.

In order to overcome this disadvantage, reactive surfactants are often used. ${ }^{23,24}$ These surfactants have a reactive group being able to react with a growing polymer chain during radical polymerization, resulting in a covalent incorporation of surface active molecules into the polymer chain. Another possibility to surmount this disadvantage is to use polymeric amphiphiles in place of conventional surfactant molecules. ${ }^{25-33}$ Although no covalent bonding is formed between the polymer amphiphile and resulting polymer particle, the polymer amphiphiles are strongly anchored to the surface of resulting particles through hydrophobic interactions. A number of studies using various amphiphilic block copolymers have demonstrated that they act as a powerful stabilizer in emulsion polymerization. ${ }^{27}$ In aqueous emulsion polymerization, hydrophobic block sequences can anchor onto the particle surface while the hydrophilic blocks extend into the water-phase and create a hydrophilic shell.

Recently, the use of block copolymer micelles as a seed for emulsion polymerization has been proposed. ${ }^{27-29}$ With the seed polymerization, it may be possible to control the final number of the particles, and hence the size of the particles, whereas in the case of emulsion polymerization with use of conventional surfactants, the particle size depends on many parameters and thus the size can not easily be predicted.

Comparing to amphiphilic block copolymers, amphiphilic random copolymers are much easier to synthesize, and one can choose a much wider range of monomers for their synthesis. Therefore, it should be worthy testing amphiphilic random copolymers for seed polymerization. There is a general trend for amphiphilic random copolymers to form micelle-like aggregates on the nanometer scale in aqueous solution due to mainly intramolecular hydrophobic associations, the association properties depending strongly

\footnotetext{
${ }^{\dagger}$ To whom correspondence should be addressed (Tel: +81-948-22-7301, Fax: +81-948-22-7334, E-mail: tendo@ me-henkel.fuk.kindai.ac.jp).

${ }^{\dagger \dagger}$ Present address: The Institute of Science and Industrial Research, Osaka University, 8-1 Mihogaoka, Ibaraki, Osaka 567-0047, Japan.
} 


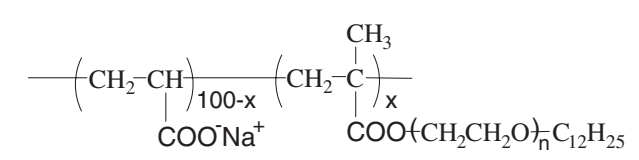

$\operatorname{NaAA} / \mathrm{DE} n \operatorname{MA}(x)$

$\begin{array}{ll}n=2, x=3,5,10,15,20 & \text { NaAA/DE2MA(3-20) } \\ n=6, x=3,5,10 & \text { NaAA/DE6MA(3-10) } \\ n=25, x=3,5,10 & \text { NaAA/DE25MA(3-10) }\end{array}$

Chart 1. Amphiphilic Polymers Used.

on the macromolecular architectures. ${ }^{34}$ Although there are some studies on the emulsion polymerization using amphiphilic random copolymers, ${ }^{9,30-33}$ much more efforts are being made with block copolymers because of their well-defined structures.

In the present study, we have developed a method to prepare polystyrene nanoparticles using amphiphilic random copolymer micelles as seeds in free-radical polymerization of styrene in aqueous media.

\section{EXPERIMENTAL}

\section{Materials}

The amphiphilic polymers used in the present study are random copolymers of sodium acrylate (NaAA) and methacrylate substituted with $\mathrm{HO}\left(\mathrm{CH}_{2} \mathrm{CH}_{2} \mathrm{O}\right)_{n^{-}}$ $\mathrm{C}_{12} \mathrm{H}_{25}$ (DEnMA) (NaAA/DEnMA $(x)$ in Chart 1, where $x$ denotes mol \% DEnMA content). These amphiphilic polymers were synthesized and their associative properties were characterized according to the methods reported elsewhere. ${ }^{34,35}$ According to the method, $\mathrm{x}$ is determined by the molar fraction of DEnMA in the copolymerization ${ }^{35}$ and $\mathrm{n}$ is determined from that of $\mathrm{HO}\left(\mathrm{CH}_{2} \mathrm{CH}_{2} \mathrm{O}\right)_{n} \mathrm{C}_{12} \mathrm{H}_{25}$ commercially supplied.

These polymers form micelles in dilute aqueous solutions due to intramolecular associations of dodecyl groups. As the polymer concentration is increased, however, they tend to associate in an intermolecular fashion and form micelles with larger sizes.

Styrene was distilled under reduced pressure prior to use for polymerization. The other reagents were used as received.

\section{Seed Polymerization}

The amphiphilic random copolymer was first dissolved in pure water and the aqueous solution was heated at $90^{\circ} \mathrm{C}$ for $30 \mathrm{~min}$ to effect complete dissolution. ${ }^{36}$ No electrolysis is added in the system. The polymer aqueous solution and a predetermined amount of styrene were placed in a three-neck, round-bottom flask equipped with a reflux condenser and an Ar inlet. The reaction mixture was stirred with a magnetic stirring bar under an $\mathrm{Ar}$ atmosphere at $70{ }^{\circ} \mathrm{C}$ for $30 \mathrm{~min}$, followed by the addition of an aqueous solution of potassium persulfate (KPS). The reaction mixture was kept at $70^{\circ} \mathrm{C}$ for $12 \mathrm{~h}$. The Ar blanket was maintained during the polymerization. The resulting polystyrene colloidal suspension was highly stable; it stayed as such even after 500d without any sign of flocculation. A representative example for the polymerization is as follows: Styrene $(25 \mathrm{~mL})$ was added to a solution of $100 \mathrm{mg} \mathrm{NaAA} / \mathrm{DE} n \mathrm{MA}(x)$ in $500 \mathrm{~mL}$ water, and the mixture was purged with $\mathrm{Ar}$ at $70^{\circ} \mathrm{C}$ under stirring for $30 \mathrm{~min}$. To this stirred mixture, a small amount of an aqueous solution containing $50 \mathrm{mg}$ of KPS was added. At given time intervals during the polymerization, $\sim 2 \mathrm{~mL}$ samples were withdrawn for analysis. To these samples, $1 \mathrm{mg}$ of 4-tertbutylcatechol was immediately added to stop the polymerization. The polymerization mixture was washed with $n$-hexane three times to remove styrene monomer. Then, the aqueous layer was transferred into a wide-opened vial, and the vial was placed in an oven at $60^{\circ} \mathrm{C}$ until water was evaporated to dryness. The conversion of styrene was determined gravimetrically from the weight of resulting polystyrene.

\section{Characterization of Polystyrene Particle Size}

The particle size was measured using a dynamic light scattering spectrometer (Otsuka Electronics Photal ELS8000) equipped with a $10 \mathrm{~mW} \mathrm{He}-\mathrm{Ne}$ laser operating at $\lambda=633 \mathrm{~nm}$. All sample solutions were diluted with aqueous $\mathrm{NaCl}$ in order to disturb the coulomb interaction among particles. The ionic strength of the sample solution was kept at 0.01 . All measurements were conducted at $25^{\circ} \mathrm{C}$.

The morphology of the polystyrene particles was observed by a field emission scanning electron microscope (FE-SEM) (Hitachi S-4300SE/N). Samples for SEM observations were prepared as follows: A small amount of a polystyrene colloidal solution was placed into a wide-opened vial, and the solution was air-dried at $60^{\circ} \mathrm{C}$ in an oven. The residual solid was scattered on a carbon tape attached on a stage and coated with Pt-Pd by a vacuum vapor deposition technique.

\section{RESULTS AND DISCUSSION}

Figure 1 shows the result of the time-conversion experiment. The polymer we used in this experiment was NaAA/DE2MA(3). As we see in Figure 1, the percent conversion of styrene increases with polymerization time, reaching a saturation level of $\sim 93 \%$ at ca. $300 \mathrm{~min}$. Then the polymerization slows down considerably, the conversion eventually reaching $99 \%$ $20 \mathrm{~h}$ after the polymerization was started (data not shown). In Figure 1, the time evolution of the size 
of resulting polystyrene particles is also presented. The diameter of the particle determined by DLS increases with time and reaches a maximum size of $\sim 200 \mathrm{~nm}$ when the conversion reaches the saturated level.

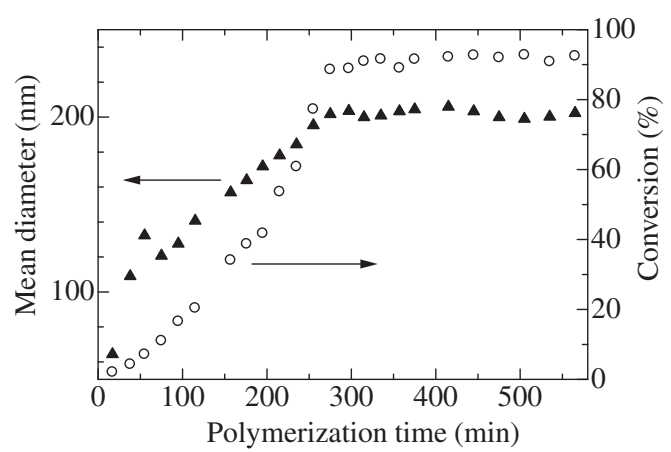

Figure 1. Monomer conversion (open circles) and the particle size determined by DLS (closed triangles) plotted as a function of time for polymerization of styrene (initial concentration, $45 \mathrm{~g} / \mathrm{L}$ ) in the presence of $0.2 \mathrm{~g} / \mathrm{L} \mathrm{NaAA} / \mathrm{DE} 2 \mathrm{MA}(3)$.
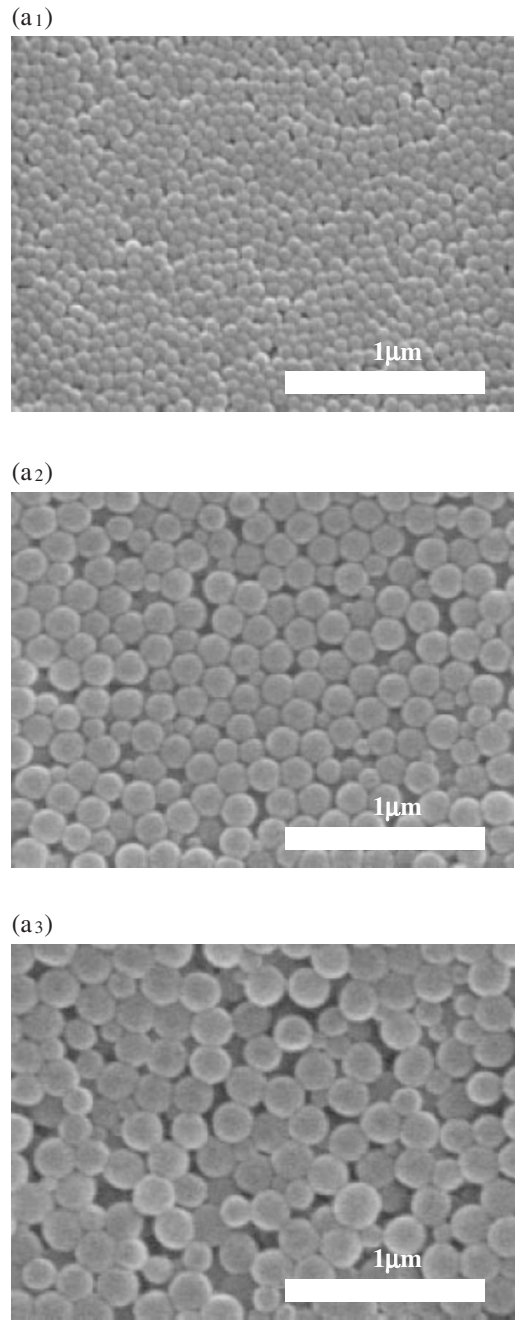

Figure 2 represents SEM images and the distributions of the particle diameters determined by DLS for the polystyrene particles formed at polymerization times of 38, 195, and $415 \mathrm{~min}$. It is clearly seen that the particles are unimodal and the mean size of the particles increases with polymerization time.

Figure 3 shows a relationship between the conversion and the mean volume of the particle calculated from the diameter as $(4 \pi / 3) \times(\text { diameter } / 2)^{3}$. The mean volume of the resulting particles increases almost linearly with the monomer conversion. This means that the number of the polystyrene particles is kept constant during the polymerization. Thus, it can be concluded that a certain number of 'juvenile' particles are formed at the initial stage of the polymerization, and the particles grow in size as the polymerization proceeds with no further new particles being created during the polymerization process. This is characteristic of the seed polymerization where micelles of the amphiphilic copolymer act as seeds,
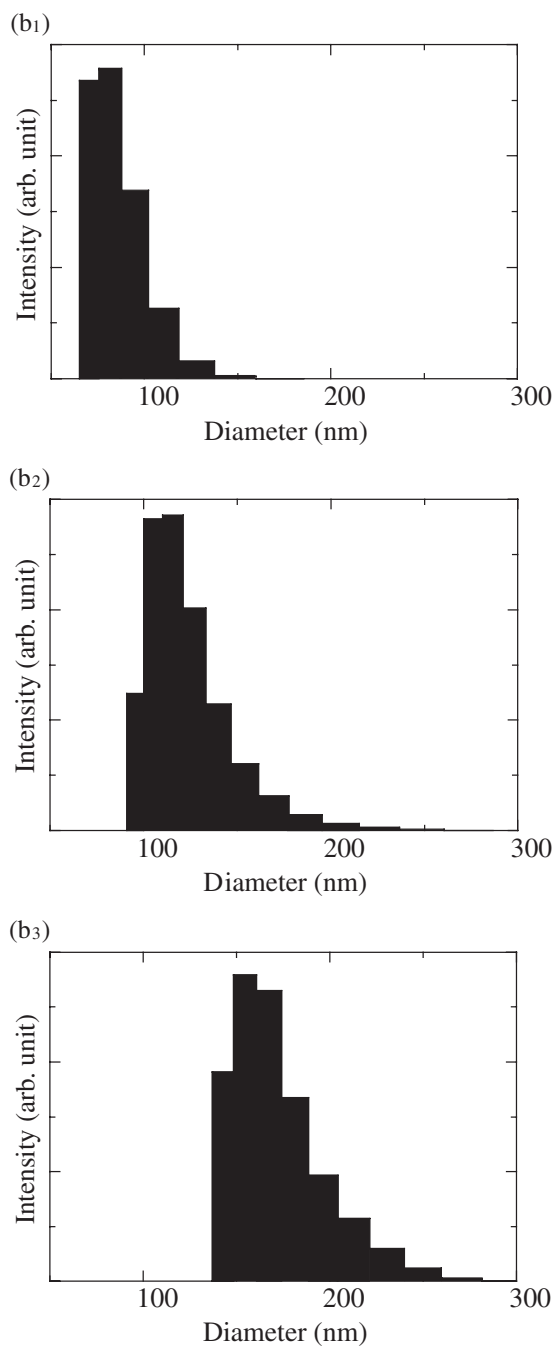

Figure 2. SEM images of polystyrene particles $\left(a_{1-3}\right)$ and the particle size distributions measured by DLS $\left(b_{1-3}\right)$ for samples obtained at different polymerization times, $\left(a_{1}\right.$ and $\left.b_{1}\right) 38 \mathrm{~min},\left(a_{2}\right.$ and $\left.b_{2}\right) 195 \mathrm{~min}$, and $\left(a_{3}\right.$ and $\left.b_{3}\right) 415 \mathrm{~min}$; the initial concentration of styrene is $45 \mathrm{~g} /$ $\mathrm{L}$ in the presence of $0.2 \mathrm{~g} / \mathrm{L} \mathrm{NaAA} / \mathrm{DE} 2 \mathrm{MA}(3)$. 


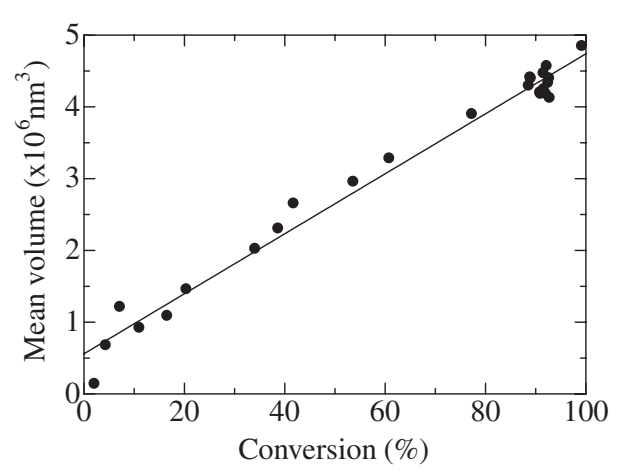

Figure 3. Relationship between the mean volume of the particles and the monomer conversion for the polymerization of styrene (initial concentration, $45 \mathrm{~g} / \mathrm{L}$ ) in the presence of $0.2 \mathrm{~g} / \mathrm{L}$ $\mathrm{NaAA} / \mathrm{DE} 2 \mathrm{MA}(3)$.

and the grow-up of the particle occurs within the micelles. In this case, adsorbing the polystyrene small precipitates is more favorable for the grow-up mechanism than absorbing styrene monomer because the amphiphilic copolymer does not adsorb styrene monomer so much, as we have already mentioned. Nevertheless, after styrene slightly solved in the micelles turns into polystyrene, it might work as a seed because of its strong affinity for styrene monomer.

In Figure 1, the intercept of straight line with the mean volume axis represents the volume of the seed amphiphilic copolymer. We also tried measuring the size directly by DLS measurement, but the concentration of the copolymer is too thin that we could not obtain the value.

In order to confirm the seed polymerization mechanism, we measured the size of the polystyrene particles obtained with varying amounts of styrene monomer. In this experiment, we used NaAA/DE2MA(3) as in the time-conversion experiment.

When NaAA/DE2MA(3) acts as a seed in polymerization, the number of the particles during the polymerization should be constant, and hence the particle diameter $(D)$ can be expressed as

$$
D^{3}=b[M]+V s
$$

where $b$ is the constant and $V s$ is the volume of the seed particle.

Figure 4 shows the mean volume plotted as a function of the initial concentration of styrene in the polymerization mixture. It can be seen that the volume increases almost linearly as the initial concentration of the monomer increases. The straight line represents the best-fitted line based on eq 1 . This means that the number of the particles does not depend on the concentration of styrene. Note that this data does not obey Smith-Ewart law, ${ }^{37}$ in which the particle number $\mathrm{N}$ is proportional to $\mathrm{A}^{3 / 5}$, where $\mathrm{A}$ denotes the total

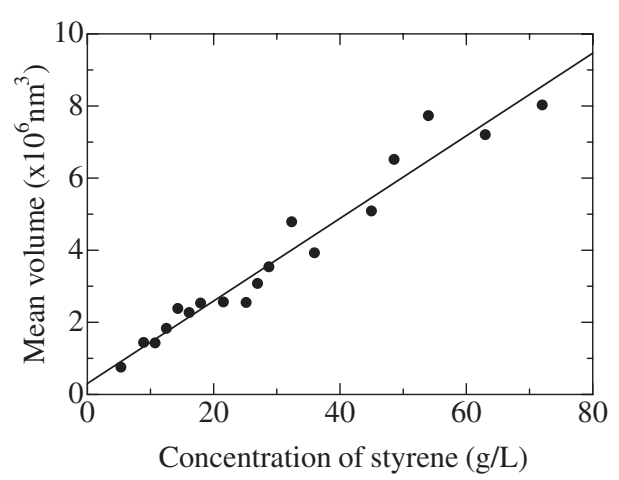

Figure 4. Mean volume of polystyrene particles plotted as a function of the initial concentration of styrene for polymerization in the presence of $0.2 \mathrm{~g} / \mathrm{L} \mathrm{NaAA} / \mathrm{DE} 2 \mathrm{MA}(3)$.

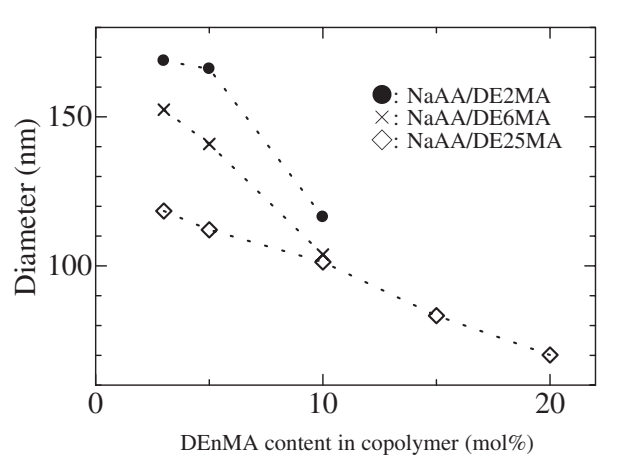

Figure 5. Dependence of the particle mean diameter against the architectures of additive amphiphilic polymer, recipe: water $50 \mathrm{~mL}$, styrene $1 \mathrm{~mL}$, KPS $5 \mathrm{mg}$ and the amphiphilic polymer $10 \mathrm{mg}$.

surface area of the particles. Using their assumption, the particle volume must be proportional to $[\mathrm{M}]^{1 / 2}$, but actually not.

The particle size was found to depend strongly on the architecture of the amphiphilic copolymer. As can be seen from Figure 5, the particle size is monotonically decreases as the DEnMA content in NaAA/ $\operatorname{DE} n \operatorname{MA}(x)$ increases. It appears that, comparing the length of the EO chain $(n)$ in the DEnMA unit for the copolymers with low DEnMA contents, the particle size is smaller for the copolymers with longer EO chains.

Since the formation mechanism is seed polymerization, the size of the polystyrene particles are determined solely from the number of the amphiphilic copolymer particles and their sizes, which depends on the intra- and intermolecular self-association of the amphiphilic copolymer. Although the reason of the relation between the particle size and the architecture of the amphiphilic polymer is still unclear, it must be brought via the self-association phenomenon, which is strongly depends on the architecture of the amphiphilic polymers. ${ }^{34,35}$ 


\section{CONCLUSION}

Monodisperse colloidal particles of polystyrene with diameters ranging from 70 to $250 \mathrm{~nm}$ were prepared by seed polymerization in water using a polymer micelle formed from a random copolymer of sodium acrylate and an EO-based surfactant monomer (surfmer) as a seed. The mean size of the particle was dependent on the ratio of styrene to the seed polymer and also on the architecture of the amphiphilic copolymer, i.e., the content of the DEnMA and the length of the EO chain in the DEnMA unit. The mean volume of the resulting particles increases almost linearly with increasing monomer conversion, indicating that the number of the particles is almost constant during the polymerization. This is a manifestation of seed polymerization where the particles grow in size as the polymerization proceeds due to the buildup of polystyrene within the particles.

Acknowledgment. We acknowledge Prof. Masakuni Yoshihara (Kinki Univ.), Dr. Henmei Ni (The National Institute for Materials Science), and Dr. Hiroshi Morikawa (Kinki Univ.) for their helpful discussions. We acknowledge for allowing us to an FESEM (Hitachi S-4300SE/N) of the Department of Biological and Environmental Chemistry, School of Humanity-Oriented Science and Engineering, Kinki University.

\section{REFERENCES}

1. C. S. Kan, J. Coat. Technol., 71, 89 (1999).

2. A. Yfantis, I. Paloumpaa, D. Schmeisera, and D. Yfantisb, Surf. Coat. Technol., 151-152, 400 (2002).

3. L. N. Butler, C. M. Fellows, and R. G. Gilbert, Prog. Org. Coat., 53, 112 (2005).

4. S. Nagaoka, H. Tobata, Y. Takiguchi, T. Satoh, T. Sakurai, M. Takafuji, and H. Ihara, J. Appl. Polym. Sci., 97, 149 (2005).

5. H. Ono, T. Matsuno, and Y. Shimatani, Jpn. Patent 026229 (2000).

6. I. Nagai and M. Nishikawa, Jpn. Patent 06045534 (1994).

7. T. Nakane and K. Tomita, in "Technologies and Applications of Polymeric Ultramicrospheres," Soichi Muroi, Ed., CMC Inc., 2001, Chapter 5, Section 4, p 254 (in Japanese) and references there in.

8. K Fujioka and T. Fujiwara, Jpn. Patent 1947028 (1994).

9. K. M. Schoisky and R. M. Fitch, J. Controlled Release, 3, 87 (1986).

10. S. M. Raboni, M. B. Nogueira, V. M. Hakim, V. T. G. Torrecilha, H. Lerner, and L. R. V. Tsuchiya, Am. J. Clin. Pathol., 117, 392 (2002).
11. S. M. Lipson and K. A. Zelinsky-Papez, Am. J. Clin. Pathol., 92, 637 (1989).

12. H. Kohno, S. Akihara, O. Nishio, and H. Ushijima, Pediatr. Int., 42, 395 (2000).

13. S. Cammas, K. Suzuki, C. Sone, Y. Sakurai, K. Kataoka, and T. Okano, J. Controlled Release, 48, 157 (1997).

14. D. C. Blackley, "Emulsion polymerization: theory and practice," Applied Science Publishers, London, 1975.

15. J. O. Stoffer and T. Bone, J. Polym. Sci., Part A: Polym. Chem., 18, 2641 (1980).

16. J. O. Stoffer and T. Bone, J. Dispersion Sci. Technol., 1, 37 (1980).

17. J. M. Asua, Prog. Polym. Sci., 27, 1283 (2002).

18. J. W. Vanderhoff, J. F. Vitkuske, E. B. Bradford, and T. Alflery, Jr., J. Polym. Sci., 20, 225, (1956).

19. A. R. Goodall, M. C. Wilkinson, and J. Hearn, J. Polym. Sci., Part A: Polym. Chem., 15, 2193 (1977).

20. M. S. Juang and I. M. Krieger, J. Polym. Sci., Part A: Polym. Chem., 14, 2089 (1976).

21. Y. Almog, S. Reich, and M. Lery, Br. Polym. J., 14, 131 (1982).

22. T. Ueda, K. Takeuchi, and M. Kato, J. Polym. Sci., Part A: Polym. Chem., 10, 2841 (1972).

23. K. Tauer, K. H. Goebel, S. Kosmella, K. Stähler, and J. Neelsen, Makromol. Chem., Macromol. Symp., 31, 107 (1990).

24. K. Nagai, Trends Polym. Sci., 4, 122 (1996).

25. T. Liu, H. Schuch, M. Gerst, and B. Chu, Macromolecules, 32, 6031 (1999).

26. A. Horgan and B. Vincent, J. Colloid Interface Sci., 262, 536 (2003).

27. P. Perrin, F. Millet, and B. Charleux, in "Physical Chemistry of Polyelectrolytes. Surfactant Science Series," T. Radava, Ed., Marcel Dekker Inc., 2000, Chapter 13, p 363.

28. T. Rager, W. H. Meyer, G. Wegner, K. Mathauer, W. Mächtle, W. Schrof, and D. Urban, Macromol. Chem. Phys., 200, 1681 (1999).

29. C. Burguiere, S. Pascual, C. Bui, J. P. Vairon, and B. Charleux, Macromolecules, 34, 4439 (2001).

30. D.-Y. Lee and J.-H. Kim, J. Appl. Polym. Sci., 69, 543 (1998).

31. Y.-J. Park, D.-Y. Lee, and J.-H. Kim, Colloids Surf., A, 139, 49 (1998).

32. D.-Y. Lee, J.-H. Kim, and U, Tae-Ik Min, Colloids Surf., A, 153, 89 (1999).

33. S. Kato, K. Sato, D. Maeda, and M. Nomura, Colloids Surf., A, 153, 127 (1999).

34. A. Hashizume, T. Noda, and Y. Morishima, in "StimuliResponsive Water Soluble and Amphiphilic Polymers." ACS Symposium Series 780, Charles L. McCormick, Ed., American Chemical Society, 2001, Chapter 2, p 14.

35. T. Noda, A. Hashizume, and Y. Morishima, Polymer, 42, 9243 (2001).

36. H. Yamamoto, A. Hashizume, and Y. Morishima, Polym. J., 32, 745 (2000).

37. W. V. Smith and R. H. Ewart, J. Chem. Phys., 16, 592 (1948). 